\title{
Catalytic steam reforming of bio-oil model compounds for hydrogen-rich gas production using bio-char as catalyst
}

\author{
Zhong Ma, Rui Xiao*, Huiyan Zhang \\ Key Laboratory of Energy Thermal Conversion and Control of Ministry of Education, School of Energy and \\ Environment, Southeast University \\ Sipailou 2\#, Nanjing, Jiangsu Province, 210096, China
}

\begin{abstract}
Hydrogen-rich gas production from the catalytic steam reforming of bio-oil model compounds was carried out in a fixed bed reactor. Bio-char, which was obtained from biomass gasification process and contained many alkali and alkaline metallic (AAEM) species, was used as a catalyst. The results showed that bio-char was effective in enhancing catalytic steam reforming of bio-oil model compounds and producing hydrogen rich gas. Temperature, S/B and WHSV were the operating variables which affected to a great extent of hydrogen production. The yield and concentration of hydrogen reached high values of $89.13 \%$ and $75.97 \%$, respectively, under the condition of $900{ }^{\circ} \mathrm{C}, \mathrm{S} / \mathrm{B}$ of 3 and $\mathrm{WHSV}=1$. Acid treatment of bio-char was conducted to investigate the effect of inherent AAEM species on the catalytic activity of bio-char. It was found that the inherent AAEM species appear to have significant effect on the catalytic activity of bio-char especially the water-gas shift reaction under the current experimental conditions.
\end{abstract}

Keywords: Hydrogen-rich gas production, bio-char, bio-oil model compounds, inherent AAEM species, catalytic steam reforming.

\section{Introduction}

Hydrogen has many advantages due to its high combustion efficiency, nonpolluting and light weight, which make it able to be considered as an ideal energy medium and alternative to fossil fuels such as oil and coal[1,2]. Biomass is one of the most abundant renewable resources available for hydrogen production by thermo-chemical processes or biological processes. In recent years, various technologies have been developed about the steam reforming of bio-oil for hydrogen production[3-5]. A major advantage for this process is that bio-oil is much easier and less expensive to transport than either biomass or hydrogen[6,7].

However, bio-oil is a mixture of hundreds of components, such as carboxylic acids, aldehydes, ketones, alcohols and phenols, which was significant influenced by the type of biomass and reaction conditions[8,9]. Thus, model compounds are often used to research the catalytic activity of reforming catalyst. One of the great challenges in the developing bio-oil reforming process is to reduce the content of tar which often cause the coking, blockage or other problems. A variety of catalysts such as minerals[10,11], Ni-based catalysts[12,13] and Iron-based catalysts[14,15] have been studied in tar reforming. These catalysts have the high activity to reform tar, but they are expensive and can be easily deactivated or poisoned in the reforming process. Some previous studies[16-20] have clearly indicated that char or ash form biomass and coal have high activity for bio-oil reforming. However, char is an effective catalyst for light components removal but lacks sufficient reactivity for heavy components[20,21]. The coke deposited on the surface of char can block the pores and reduce the surface area, thus it lead to decrease the activity of char. However, the deposited coke can be converted by gasification or reforming agents, such as steam, $\mathrm{O}_{2}$ and $\mathrm{CO}_{2}$, which would inhibit its deactivation through producing new pores[18,22]. If deactivated, these catalysts can be simply burned or gasified to recover their energy without the need of regeneration[23].

Biomass may contain a significant amount of inherent alkali and alkaline metallic (AAEM) species as a result of nutrients uptake during growth[24]. After biomass gasification, most of the inherent AAEM species may be retained in the char. It is well-known that AAEM species had catalytic activity for bio-oil reforming due to alkali (K, Na) and Corresponding author. Tel.: +86 25 83795726; fax: +86 25 83795508. E-mail: ruixiao@ seu.edu.cn ( Rui Xiao) 
alkaline earth metals ( $\mathrm{Mg}, \mathrm{Ca}$ ) can significantly promote the stability of the catalyst by increasing the water adsorption on the surface[25,26]. Kongvui Yip[27] studied the effect of alkali and alkaline metallic (AAEM) species on bio-char reactivity and syngas compositions during steam gasification. The results indicated that $\mathrm{Na}, \mathrm{K}$ and $\mathrm{Ca}$ retained in the bio-chars are the key catalytic species, with the catalytic effect appearing to be in the order $\mathrm{K}>\mathrm{Na}>\mathrm{Ca}$ during the steam gasification reaction of these bio-chars. Daniel Mourant[28] studied the effects of alkali and alkaline earth metallic species on the yield and composition of bio-oil. The results indicated that the removal of AAEM species did not result in significant changes in the yields of bio-oil and bio-char. However, the bio-oil properties, e.g. viscosity, were drastically affected by the removal of AAEM species. Furthermore, with the utilization of low cost bio-char, the economics of hydrogen production from bio-oil catalytic reforming can be improved dramatically. Another advantage of using bio-char based catalysts for bio-oil reforming is that carbon-based catalysts are quite resistant to deactivation by sulfur-containing bio-oil. Therefore, bio-char have great potential to be the catalyst in bio-oil reforming process.

In this paper, bio-char, as a by-product of the biomass gasification process, was used as catalyst in the catalytic steam reforming of bio-oil model compounds for hydrogen rich gas production in a fixed bed reactor. Our objective is to study the catalytic behavior of bio-char and the effect of inherent AAEM species on the catalytic activity of bio-char.

\section{Experimental and methods}

\subsection{Bio-oil model compounds}

The bio-oil model compounds was obtained by the blend of acetic acid $\left(\mathrm{CH}_{3} \mathrm{COOH}\right)$, m-cresol $\left(\mathrm{C}_{7} \mathrm{H}_{8} \mathrm{O}\right)$, furfural $\left(\mathrm{C}_{5} \mathrm{H}_{4} \mathrm{O}_{2}\right)$ and acetone $\left(\mathrm{CH}_{3} \mathrm{COCH}_{3}\right)$. All reagents were analytical grade and provided by Sinopharm Chemical Reagent Co. Ltd. (Beijing, China).

\subsection{Bio-char preparation}

Bio-char used in this study was obtained as the by-product of biomass gasification process. The ultimate and proximate analysis of the bio-char were reported in Table 1.

AAEM species were removed by submitting the bio-char to washing with dilute hydrochloric acid (10 wt. \%) for $5 \mathrm{~h}$ at room temperature. The bio-char sample was then rinsed with deionised water until neutrality was achieved. All samples were filtered with a $30 \mu \mathrm{m}$ stainless steel mesh to separate the bio-char from the leaching water before being dried and weighed.

The alkali and alkaline earth metallic (AAEM) species in bio-char were quantified using X-ray fluorescence spectrometer (XRF-1800). The result of AAEM species analysis were reported in Table 2.

2.3 Apparatus and procedures

A schematic flow sheet was shown in Fig. 1. The apparatus include syringe pump, fixed bed reactor, thermocouple, temperature controller, mass flow controller, cooler, dryer and gas analyzer. The fixed bed reactor was made up of stainless steel with a length $60 \mathrm{~cm}$ and an inner diameter $25 \mathrm{~mm}$. A porous distributor was installed at $30 \mathrm{~cm}$ from the bottom of the reactor to support the bed material. The heat was provided by an electric furnace and the reaction temperature was monitored and controlled by a thermocouple. The liquid feedstock was fed into the reactor by using a syringe pump. The experimental temperature was controlled between $750{ }^{\circ} \mathrm{C}$ and $900{ }^{\circ} \mathrm{C}$ in $50{ }^{\circ} \mathrm{C}$ steps, S/B (steam to bio-oil model compounds ratio) was varied from 1 to 7 and WHSV (weight hourly space velocity) was between 1 to 4 . The quartz was used in the comparison experiment with no catalyst.

In this study, before each experiment the bio-char was treated with steam to remove the volatile matter and fixed carbon for $1 \mathrm{~h}$ at $900{ }^{\circ} \mathrm{C}$. The ultimate analysis of the bio-char after steam pretreatment are reported in Table 3. The BET results were measured by Brunauer Emmett Teller (BET) method (ASAP 2000), and shown in Table 4.

\subsection{Product analysis}

Non-condensable gases composed of $\mathrm{H}_{2}, \mathrm{CO}, \mathrm{CO}_{2}$ and $\mathrm{CH}_{4}$ were analyzed by infrared gas analyser (Gasboard-3100). 


\subsection{Data analysis}

The basic chemical formula of bio-oil model compounds is assumed as $\mathrm{C}_{\mathrm{n}} \mathrm{H}_{\mathrm{m}} \mathrm{O}_{\mathrm{z}}$. It could be only obtained $\mathrm{H}_{2}$ and $\mathrm{CO}_{2}$ if the bio-oil model compounds and $\mathrm{H}_{2} \mathrm{O}$ can be totally reactive. Then the maximum stoichiometric hydrogen yield can be obtained when the steam reforming reaction of the bio-oil model compounds goes to completion as follows:

$$
\mathrm{C}_{n} \mathrm{H}_{m} \mathrm{O}_{z}+(2 n-z) \mathrm{H}_{2} \mathrm{O} \rightarrow(2 n+m / 2-z) \mathrm{H}_{2}+n \mathrm{CO}_{2}
$$

Hydrogen yield can be defined as Eq. (2):

$$
Y=\frac{n_{H_{2}}}{\mathrm{n}_{\mathrm{H}_{2}^{0}}} \times 100 \%
$$

In Eq. (2), $\mathrm{n}_{\mathrm{H}_{2}}$ is moles of $\mathrm{H}_{2}$ obtained and $\mathrm{n}_{\mathrm{H}_{2}^{0}}$ is moles of $\mathrm{H}_{2}$ in stoichiometric potential.

\section{Results and discussion}

\subsection{Influence of bio-char}

The purpose of using bio-char in catalytic steam reforming of bio-oil model compounds includes: (1) bio-char containing large concentrations of AAEM, which can enhance $\mathrm{H}_{2} \mathrm{O}$ adsorption and facilitate the formation of reactive hydroxyl groups and their subsequent steam reforming reactions with carbon precursors $\left(\mathrm{CH}^{*}\right.$ and $\left.\mathrm{CH}_{3} \mathrm{C}^{*}\right)[29,30] ;(2)$ bio-char had a relative high surface area and a well developed mesoporous structure, which can provide more active sites for reforming reactions.

The involved reactions in catalytic steam reforming of bio-oil model compounds were shown as follows:

Bio-oil model compounds cracking reactions: $\mathrm{C}_{n} \mathrm{H}_{m} \mathrm{O}_{z} \rightarrow \mathrm{H}_{2}+\mathrm{CO}+\mathrm{CH}_{4}+\mathrm{CO}_{2}+\mathrm{C}$

Steam reforming methane reaction: $\mathrm{CH}_{4}+\mathrm{H}_{2} \mathrm{O} \rightarrow \mathrm{CO}+3 \mathrm{H}_{2}$

Water gas reaction: $\mathrm{C}+\mathrm{H}_{2} \mathrm{O} \rightarrow \mathrm{CO}+\mathrm{H}_{2}$

Boudouard reaction: $\mathrm{C}+\mathrm{CO}_{2} \rightarrow 2 \mathrm{CO}$

Water-gas shift reaction: $\mathrm{CO}+\mathrm{H}_{2} \mathrm{O} \rightarrow \mathrm{CO}_{2}+\mathrm{H}_{2}$

The bio-char as catalyst was filled in the fixed bed reactor for steam reforming of bio-oil model compounds and improving gas quality, in comparison with the case without catalyst. Table 5 showed the hydrogen yield and gas composition from catalytic steam reforming in a comparison of no catalyst and bio-char performance, and some typical operating conditions were also reported in Table 5. It can be seen that the hydrogen yield and hydrogen concentration in the absence of catalyst was $38.16 \%$ and $50.74 \%$, respectively. However, when bio-char was used as catalyst, there were marked increases in hydrogen yield and hydrogen concentration, which were $66.80 \%$ and $65.91 \%$, respectively. This indicated that bio-char have demonstrated a better performance for steam reforming of bio-oil model compounds and produce hydrogen rich gas. The significant increase in hydrogen yield was due to bio-char promote the reactions Eqs.(3)-(7). A similar finding on other catalysts for biomass catalytic gasification was also reported by Lv et al.[31].

Table 5 also showed the percentage in volume of product gas components from catalytic steam reforming. The results showed that the main gas products were $\mathrm{H}_{2}, \mathrm{CO}, \mathrm{CH}_{4}$ and $\mathrm{CO}_{2}$. Compared the case absence of catalyst, it could be seen in Table 4 that the concentration of hydrogen in the process with bio-char as catalyst was improved over 15 vol\%; $\mathrm{CO}$ and $\mathrm{CO}_{2}$ content has a marked decrease; most of $\mathrm{CH}_{4}$ was converted. From these changes of gas composition, it could be concluded that several important reactions (Eqs. (3)-(7)), such as the water-gas shift reaction and steam reforming 
methane reaction, occurred in the catalytic steam reforming process simultaneously. All those reactions are favorable for hydrogen generation, thus the content of $\mathrm{H}_{2}$ in gas increased significantly. Compared with non-catalyst process, $\mathrm{CO}$, $\mathrm{CH}_{4}$ and $\mathrm{CO}_{2}$ content exhibited a drop trend with the bio-char catalyst.

Overall, the bio-char enhanced markedly the catalytic steam reforming of bio-oil model compounds and generated hydrogen rich gas. Particularly, the content of $\mathrm{H}_{2}$ in gas components was enhanced significantly while that of $\mathrm{CH}_{4}$ was decreased markedly. The hydrogen yield in catalytic steam reforming with bio-char reached to $66.80 \%$, which was about double than that without catalyst under the same conditions. Therefore, the bio-char was effective in enhancing catalytic steam reforming of bio-oil model compounds and producing hydrogen rich gas.

\subsection{Influence of reaction temperature}

The reaction temperature is the most important operating variables for steam reforming of bio-oil model compounds, because the main reactions are endothermic. The effect of temperature in the range from $750{ }^{\circ} \mathrm{C}$ to $900{ }^{\circ} \mathrm{C}$ on hydrogen yield and gas composition was investigated while S/B (steam to bio-oil model compounds ratio) and WHSV (weight hourly space velocity) were fixed at 3 and 2, respectively. The results were presented in Fig. 2.

As shown in Fig. 2, hydrogen yield increased with increasing reaction temperature. The hydrogen yield increased from $62.86 \%$ to $87.16 \%$ as the increasing reaction temperature from $750{ }^{\circ} \mathrm{C}$ to $900{ }^{\circ} \mathrm{C}$. As expected, the increase in temperature led to higher hydrogen yield. The effect of reaction temperature on hydrogen yield could be due to various reasons, such as: (i) higher temperature benefits bio-oil model compounds cracking and produce more small molecule components ie. Eq.(3); (ii) steam reforming methane reaction and Water gas reaction are endothermic according to Eq. (4) and (5) which are favored at higher temperature.

Fig. 2 also showed that the effect of temperature on gas composition. As is observed, the composition of the gas products were found to be strongly influenced by changes in temperature. With the temperature increasing from $750{ }^{\circ} \mathrm{C}$ to $850^{\circ} \mathrm{C}$, the significant decreases in $\mathrm{CH}_{4}, \mathrm{CO}_{2}$ and increases in $\mathrm{H}_{2}, \mathrm{CO}$ were observed which can be ascribed to the high temperature enhancing the endothermic reactions and higher catalytic activity of bio-char at higher temperatures[32]. The endothermic reactions in the catalytic steam reforming process include steam reforming methane reaction (Eq. (4)), water-gas reaction (Eq. (5)) and boudouard reaction (Eq. (6))[33]. Bio-oil model compounds can be adsorbed on the active sites of bio-char particles. The adsorbed bio-oil model compounds and cokes formed can be catalytically reformed to $\mathrm{CO}$ and $\mathrm{H}_{2}$ by water gas reaction and boudouard reaction. The water gas reaction cannot only increase $\mathrm{CO}$ and $\mathrm{H}_{2}$ in gas, but also refresh the active surface area of bio-char at temperature above $800{ }^{\circ} \mathrm{C}$. These experimental results for char agree with findings from other researchers. Le et al.[34] tested the performance of nickel catalysts supported by brown coal char in a fluidized bed gasifier; similar to the current study, $\mathrm{H}_{2}$ and $\mathrm{CO}$ concentrations significantly increased with reaction temperature. In addition, the $\mathrm{CO}$ concentration decreases and the $\mathrm{CO}_{2}$ concentration increases when the temperature increasing from $850^{\circ} \mathrm{C}$ to $900{ }^{\circ} \mathrm{C}$, which indicated that water-gas shift reaction (Eq. (7)) played a more dominating role. Li et al. [35] found the same trend, which can be attributed to higher temperature providing more favorable conditions for thermal cracking of hydrocarbon and steam reforming. The concentration of $\mathrm{CH}_{4}$ also has a great decrease through the catalytic steam reforming process. Endothermic reaction (Eq. (4)) have mainly influence on $\mathrm{CH}_{4}$ concentration.

\subsection{Influence of steam to bio-oil model compounds ratio}

In the presence of bio-char, hydrogen yield and gas composition as functions of steam to bio-oil model compounds ratio (S/B) with temperature kept constant at $900{ }^{\circ} \mathrm{C}$ and WHSV of 2 were illustrated in Fig. 3. The S/B was controlled by keeping the bio-oil model compounds feed rate while changing the rate of steam flow at a constant feeding rate.

It was evident from Fig. 3 that with the introduction of the steam, hydrogen yield increased first from $76.87 \%$ to $87.16 \%$ as S/B rose from 1 to 3, and then dropped as steam flow rate rising continually. It was because the increased steam quantity would enhance the steam reforming reactions (Eqs. (4), (5) and (7)). However, the yield of hydrogen exhibited a decrease trend with a further increase of S/B ratio from 3 to 7 . The possible reasons were the excessive 
quantity of low temperature steam reduced the reaction temperature. The results were in agreement with previous studies [36].

In regard to the gas composition, Fig. 3 indicated that the content of $\mathrm{H}_{2}$ was increased from $66.54 \%$ to $73.97 \%$ with the S/B ratio increase from 1 to 3, while the $\mathrm{H}_{2}$ content gradually decreased with a further increase of S/B ratio. With the S/B ratio increasing from 1 to 7 , the $\mathrm{CO}_{2}$ and $\mathrm{CH}_{4}$ content increased gradually, while the content of $\mathrm{CO}$ showed a decreasing trend. This might be attributed to the promoting of the water-gas shift reaction (Eq. (7)) at the higher content of steam.

From the point of energy saving, it is necessary to select an optimal S/B ratio according to the yield of hydrogen. In the present study, the optimum value of S/B was found to be 3 .

\subsection{Influence of WHSV}

The influence of WHSV on hydrogen yield and gas composition under $900{ }^{\circ} \mathrm{C}$ and S/B of 3 was investigated, the value of WHSV ranged between 1 and 4. Fig. 4 indicated the results of $\mathrm{H}_{2}$ yield and gas composition are achieved by adopting different WHSV.

Fig. 4 showed that with the WHSV increasing from 1 to 4 , the $\mathrm{H}_{2}$ yield decreased from $89.13 \%$ to $50.14 \%$. The reason was that with the increase of WHSV, mass of bio-char became less, that is to say, flow rate of the bio-oil model compounds was so high that it could not totally reacted. Some unconverted components were entrained out reactor by the generated gas, and the $\mathrm{H}_{2}$ yield decreased, which is in agreement with the results of Ref.[9,37].

The effect of WHSV on gas composition was also studied and plotted in Fig.4. From Fig.4, it can be seen that the composition of the gas products were found to be strongly influenced by changes in the WHSV. As the WHSV increased from 1 to 4, the contents of $\mathrm{H}_{2}$ and $\mathrm{CO}_{2}$ were decreased, while the contrary trend appeared for the contents of $\mathrm{CO}$ and $\mathrm{CH}_{4}$. It was explained by the presence of more bio-char namely lower WHSV value, which revealed better catalytic activity, and improved the content of hydrogen. On the other hand, WHSV indicates the gas residence time in the reactor[32,38], lower WHSV value means longer gas residence time, which can promote the catalytic steam reforming of bio-oil model compounds and produce more hydrogen-rich gas.

\subsection{Influence of AAEM species}

From Table 2, the AAEM species contents in the acid-treated bio-char are significantly lower than that in the raw bio-char. The influence of AAEM species on the catalytic activity of bio-char was conducted at the reaction temperature of $900{ }^{\circ} \mathrm{C}, \mathrm{S} / \mathrm{B}$ of 3 and WHSV of 1 . The experimental results were presented in Table 6.

Table 6 showed the hydrogen yield and gas composition from catalytic steam reforming in a comparison of acid-treated bio-char and raw bio-char, and some other operating conditions were also reported in Table 6. It can be seen that the hydrogen yield and hydrogen concentration in the raw bio-char process was $89.13 \%$ and $75.97 \%$, respectively. However, when bio-char was treated with acid, there were marked decreases in hydrogen yield and hydrogen concentration, which were $70.22 \%$ and $67.82 \%$, respectively. The comparison indicated that acid treatment has a remarkable influence on the catalytic activity of bio-char. The significant decrease in hydrogen yield was due to the majority of the inherent AAEM species of bio-char were removed by acid treatment, which slow down the rate of reactions Eqs. (3)-(7)[27].

Table 6 also showed the percentage in volume of product gas components. The results showed that comparing the case of acid-treated bio-char, the concentration of $\mathrm{H}_{2}$ and $\mathrm{CO}_{2}$ in the process with raw bio-char were improved from $67.82 \%$ to $75.97 \%$ and $14.03 \%$ to $18.08 \%$, respectively. However, contrary to the trend $\mathrm{H}_{2}$ and $\mathrm{CO}_{2}, \mathrm{CO}$ has a marked decrease. The content of $\mathrm{CH}_{4}$ in the two cases were $0 \%$, which was in agreement with previous studies [39]. From these changes of gas composition, it could be concluded that the inherent AAEM species in bio-char appear to have a significant effect on the water-gas shift reaction (Eq. (7)) and insignificant effect on steam reforming methane reaction (Eq. (4)) under the present experimental conditions. The reaction of water-gas shift is favorable for hydrogen generation, 
thus the content of $\mathrm{H}_{2}$ in gas increased significantly.

From the above investigation, the inherent AAEM species in bio-char play an important role in catalytic steam reforming of bio-oil model compounds. Acid-treatment of the bio-char can significantly reduce the contents of AAEM species and the reduce the activity of bio-char. It is found that the inherent AAEM species appear to have significant effect on the water-gas shift reaction and insignificant effect on steam reforming methane reaction under the current experimental conditions.

\section{Conclusions}

Bio-char was used as catalyst in the catalytic steam reforming of bio-oil model compounds. Acetic acid, m-cresol, furfural and acetonethe were selected as bio-oil model compounds to test the bio-char performance. The yield and concentration of hydrogen reached high values of $89.13 \%$ and $75.97 \%$, respectively, at $900{ }^{\circ} \mathrm{C}, \mathrm{S} / \mathrm{B}$ of 3 and WHSV=1. The results indicated that temperature, S/B and WHSV are the key factors that influencing hydrogen yield. An operation temperature of $900^{\circ} \mathrm{C}, \mathrm{S} / \mathrm{B}$ of 3 and WHSV of 1 were selected as optimal conditions. Additional results have also shown that acid treatment could decrease the catalytic activity of bio-char, due to the loss of the inherent AAEM species which was removed from bio-char during acid treated process. It is found that the inherent AAEM species appear to have significant effect on the water-gas shift reaction and insignificant effect on steam reforming methane reaction under the current experimental conditions.

\section{Acknowledgements}

The authors gratefully acknowledge the financial support by National Natural Science Foundation of China (Grant No. 51476035) and National Science Foundation for Distinguished Young Scholars of China (Grant No. 51525601).

\section{References}

[1] S. Z. Sun, M. Zhao and R. Xiao. Performance of $\mathrm{CeO}_{2}$-modified iron-based oxygen carrier in the chemical looping hydrogen generation process. Energy \& Fuels 2015;29:7612-7621.

[2] Zhang, H. Y., Xiao, R., Song, M. and Shen, D. K.. Hydrogen production from bio-oil by chemical looping reforming. Journal of Thermal Analysis and Calorimetry 2014;115:1921-1927.

[3] X. X. Yang, Y. J. Wang and M. M Li. Enhanced hydrogen production by steam reforming of acetic acid over a Ni catalyst supported on mesoporous MgO. Energy \& Fuels 2016;3:2198-2203.

[4] Ming Fu, QingLi Xu and Suping Zhang. Hydrogen production from bio-oil model compounds dry $\left(\mathrm{CO}_{2}\right)$ reforming over $\mathrm{Ni} / \mathrm{Al}_{2} \mathrm{O}_{3}$ catalyst. International Journal of Hydrogen Energy 2016;3:1494-1501.

[5] F. Bimbela, M. Oliva, J. Ruiz, L. García and J. Arauzo. Hydrogen production via catalytic steam reforming of the aqueous fraction of bio-oil using nickel-based coprecipitated catalysts. International Journal of Hydrogen Energy 2013;38:14476-14487.

[6] Chen T, Wu C and Liu R. Steam reforming of bio-oil from rice husks fast pyrolysis for hydrogen production. Bioresource Technology 2011;102:9236-9240.

[7] Sarkar S, Kumar A. Large-scale biohydrogen production from bio-oil. Bioresource Technology 2010;101:7350-7361.

[8] Dekui Shen, Guofu Liu, Jing Zhao, Jiangtao Xue, Shipian Guan and Rui Xiao. Thermo-chemical conversion of lignin to aromatic compounds: Effect of lignin source and reaction temperature. Journal of Analytical and Applied Pyrolysis 2015;112: 56-65.

[9] Suping Zhang, Xiaojing Li, Qiyi Li, Qingli Xu and Yongjie Yan. Hydrogen production from the aqueous phase derived from fast pyrolysis of biomass. Journal of Analytical and Applied Pyrolysis 2011;92:158-163.

[10] Myrén C, Hörnell C, Björnbom E and Sjöström K. Catalytic tar decomposition of biomass pyrolysis gas with a combination of dolomite and silica. Biomass Bioenergy 2002;23:217-227.

[11] Min Z, Asadullah M, Yimsiri P, Zhang S, Wu H and Li C-Z. Catalytic reforming of tar during gasification. Part I. Steam reforming of biomass tar using ilmenite as a catalyst. Fuel 2011;90:1847-1854.

[12] Iwasa N, Yamane T and Arai M. Influence of alkali metal modification and reaction conditions on the catalytic activity and stability of $\mathrm{Ni}$ containing smectite-type material for steam reforming of acetic acid. International Journal of Hydrogen Energy 2011;36:5904-5911.

[13] Miyazawa T, Kimura T, Nishikawa J, Kado S, Kunimori K and Tomishige K. Catalytic performance of supported Ni catalysts in partial oxidation and steam reforming of tar derived from the pyrolysis of wood biomass. Catalysis Today 2006;115:254-262. 
[14] Nordgreen T, Liliedahl T and Sjostrom K. Elemental iron as a tar breakdown catalyst in conjunction with atmospheric fluidised bed gasification of biomass: a thermodynamic study. Energy \& Fuels 2006;20:890-895.

[15] Matsuoka K, Shimbori T, Kuramoto K, Hatano H and Suzuki Y. Steam reforming of woody biomass in a fluidised bed of iron oxide-impregnated porous alumina. Energy \& Fuels 2006;20:2727-2731.

[16] Zhenhua Min, Piyachat Yimsiri, Mohammad Asadullah, Shu Zhang and Chun-Zhu Li. Catalytic reforming of tar during gasification. Part II. Char as a catalyst or as a catalyst support for tar reforming. Fuel 2011;90:2545-2552.

[17] Shu Zhang, Mohammad Asadullah, Li Dong, Hui-Ling Tay and Chun-Zhu Li. An advanced biomass gasification technology with integrated catalytic hot gas cleaning. Part II: Tar reforming using char as a catalyst or as a catalyst support. Fuel 2013;112:646-653.

[18] Hosokai S., Hayashi J-I., Shimada T., Kobayashi Y., Kuramoto K and Li C-Z. Spontaneous generation of tar decomposition promoter in a biomass steam reformer. Chemical Engineering Research \& Design 2005;83:1093-102.

[19] Shurong Wang, Fan Zhang, Qinjie Cai , Xinbao Li , Lingjun Zhu , Qi Wang and Zhongyang Luo. Catalytic steam reforming of bio-oil model compounds for hydrogen production over coal ash supported Ni catalyst. International Journal of Hydrogen Energy 2014;39:2018-2025.

[20] Duo Wang, Wenqiao Yuan and Wei Ji. Char and char-supported nickel catalysts for secondary syngas clean up and conditioning. Applied Energy 2011;88:1656-1663.

[21] Gilbert P, Ryu C, Sharific V and Swithenbank J. Tar reduction in pyrolysis vapours from biomass over a hot char bed. Bioresource Technology 2009;23:6045-6051.

[22] Hayashi J-I., Iwatsuki M., Morishita K., Tsutsumi A., Li C-Z and Chiba T. Roles of inherent metallic species in secondary reactions of tar and char during rapid pyrolysis of brown coals in a drop-tube reactor. Fuel 2002;81:1977-1987.

[23] Li C-Z. Some recent advances in the understanding of the pyrolysis and gasification behaviour of Victorian brown coal. Fuel 2007;86:1664-1683.

[24] Kongvui Yip, Fujun Tian, Jun-ichiro Hayashi, and Hongwei Wu. Effect of Alkali and Alkaline Earth Metallic Species on Biochar Reactivity and Syngas Compositions during Steam Gasification.Energy \& Fuels 2010;24:173-181.

[25] Mohanty P., Patel M. and Pant KK.. Hydrogen production from steam reforming of acetic acid over Cu-Zn supported calcium aluminate. Bioresource Technology 2012;123:558-565.

[26] Ferrandon M., Mawdsley J. and Krause T.. Effect of temperature, steam-to-carbon ratio, and alkali metal additives on improving the sulfur tolerance of a $\mathrm{Rh} / \mathrm{LaeAl}_{2} \mathrm{O}_{3}$ catalyst reforming gasoline for fuel cell applications. Applied Catalysis A 2008;342:69-77.

[27] Yip K., Tian F. and Hayashi J.. Effect of Alkali and Alkaline Earth Metallic Species on Biochar Reactivity and Syngas Compositions during Steam Gasification[J]. Energy \& Fuels 2009;1:173-181.

[28] Mourant D., Wang Z. and He M.. Mallee wood fast pyrolysis: effects of alkali and alkaline earth metallic species on the yield and composition of bio-oil. Fuel 2011;9:2915-2922.

[29] Wang S, Zhang F, Cai Q, et al. Steam reforming of acetic acid over coal ash supported Fe and Ni catalysts[J]. International Journal of Hydrogen Energy, 2015, 40(35): 11406-11413.

[30] Wang S, Li X, Zhang F, et al. Bio-oil catalytic reforming without steam addition: application to hydrogen production and studies on its mechanism[J]. international journal of hydrogen energy, 2013, 38(36): 16038-16047.

[31] Lv PM., Chang J., Wang TJ., Fu Y., Chen Y and Zhu JG. Hydrogen rich gas production from biomass catalytic gasification. Energy \& Fuels 2004;18:228-233.

[32] Alauddin ZABZ., Lahijani P., Mohammadi M. and Mohamed AR.. Gasification of lignocellulosic biomass in fluidized beds for renewable energy development: a review. Renewable \& Sustainable Energy Reviews 2010;14:2852-2862.

[33] Ningbo Gao, Aimin Li, Cui Quan and Fan Gao. Hydrogen-rich gas production from biomass steam gasification in an updraft fixed-bed gasifier combined with a porous ceramic reformer. International Journal of Hydrogen Energy 2008;33:5430-5438.

[34] Le DD., Xiao X., Morishita K. and Takarada T.. Biomass gasification using nickel loaded brown coal char in fluidized bed gasifier at relatively low temperature. Journal of Chemical Engineering of Japan 2009;1:51-57.

[35] Jianfen Li, Yanfang Yin, Xuanming Zhang, Jianjun Liu and Rong Yan. Hydrogen-rich gas production by steam gasification of palm oil wastes over supported tri-metallic catalyst. International Journal of Hydrogen Energy 2009;34:9108-9115.

[36] P.M Lv, Z.H Xiong, J Chang, C.Z Wu, Y Chen and J.X Zhu. An experimental study on biomass air-steam gasification in a fluidized bed. Bioresource Technology 2004;1:95-101.

[37] F. Seyedeyn-Azad, E. Salehi, J. Abedi and T. Harding. Biomass to hydrogen via catalytic steam reforming of bio-oil over Ni-supported alumina catalysts. Fuel Processing Technology 2011;3:563-569. 
[38] Maoyun He, Bo Xiao, Shiming Liu, Xianjun Guo, Siyi Luo, Zhuanli Xu, Yu Feng and Zhiquan Hu. Hydrogen-rich gas from catalytic steam gasification of municipal solid waste (MSW): Influence of steam to MSW ratios and weight hourly space velocity on gas production and composition. International Journal of Hydrogen Energy 2009;34:2174-2183.

[39] Wang S, Cai Q, Zhang F, et al. Hydrogen production via catalytic reforming of the bio-oil model compounds: Acetic acid, phenol and hydroxyacetone[J]. International Journal of Hydrogen Energy, 2014, 39(32): 18675-18687.

\section{Figure captions:}

Fig.1: Schematic diagram of experimental apparatus.

Fig.2: Effect of temperature on gas composition and hydrogen yield.

Fig.3: Effect of S/B on gas composition and hydrogen yield.

Fig.4: Effect of WHSV on gas composition and hydrogen yield. 
Table captions:

Table 1: Ultimate analysis and proximate analysis of the bio-char. ${ }^{\mathrm{a}}$

Table 2: AAEM species analysis of the ash in bio-char (wt.\%).

Table 3: Ultimate analysis of the bio-char after steam pretreatment. ${ }^{\mathrm{a}}$

Table 4: The BET test of bio-char after steam pretreatment.

Table 5: Influence of bio-char.

Table 6: Effect of AAEM species on the catalytic activity of bio-char. 


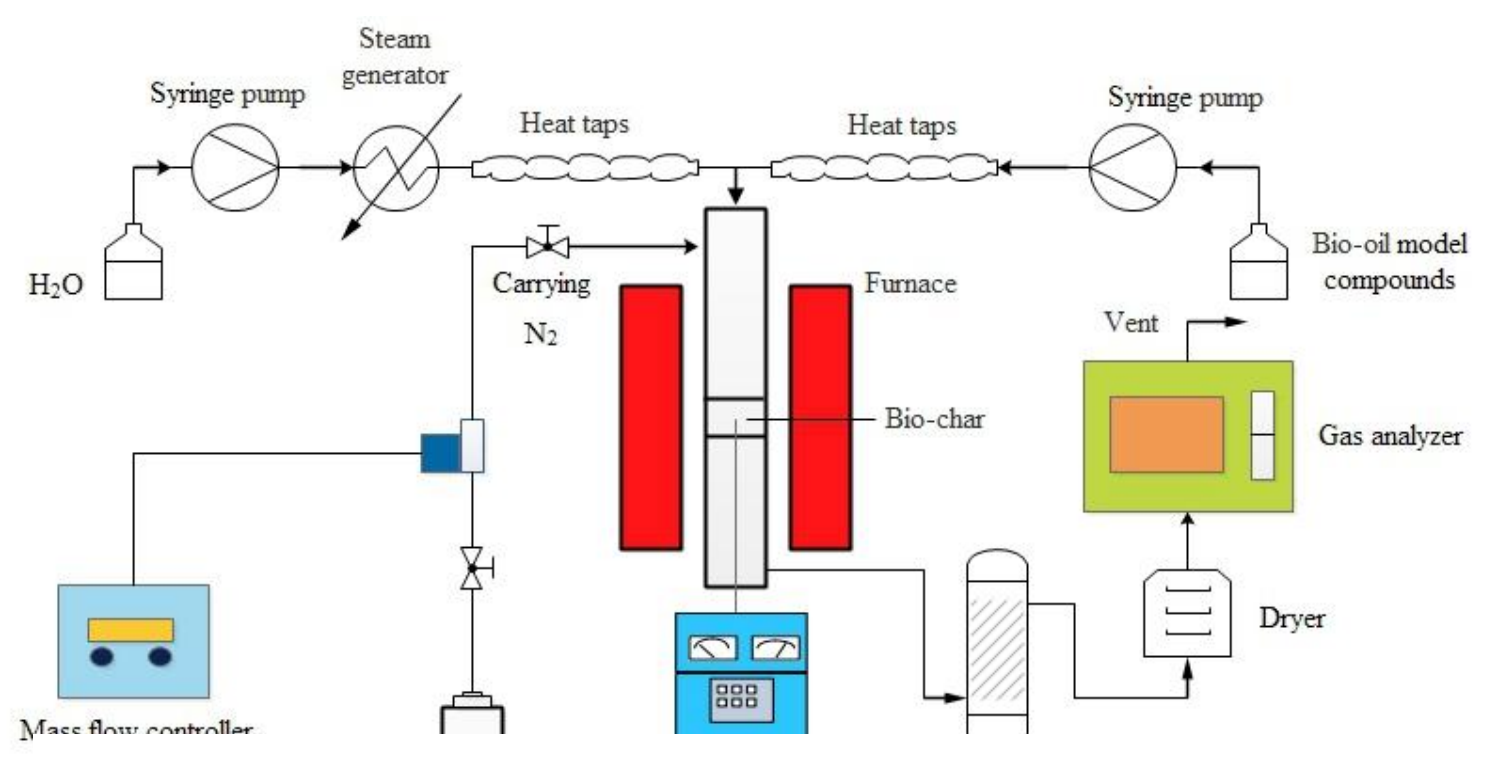

Fig. 1

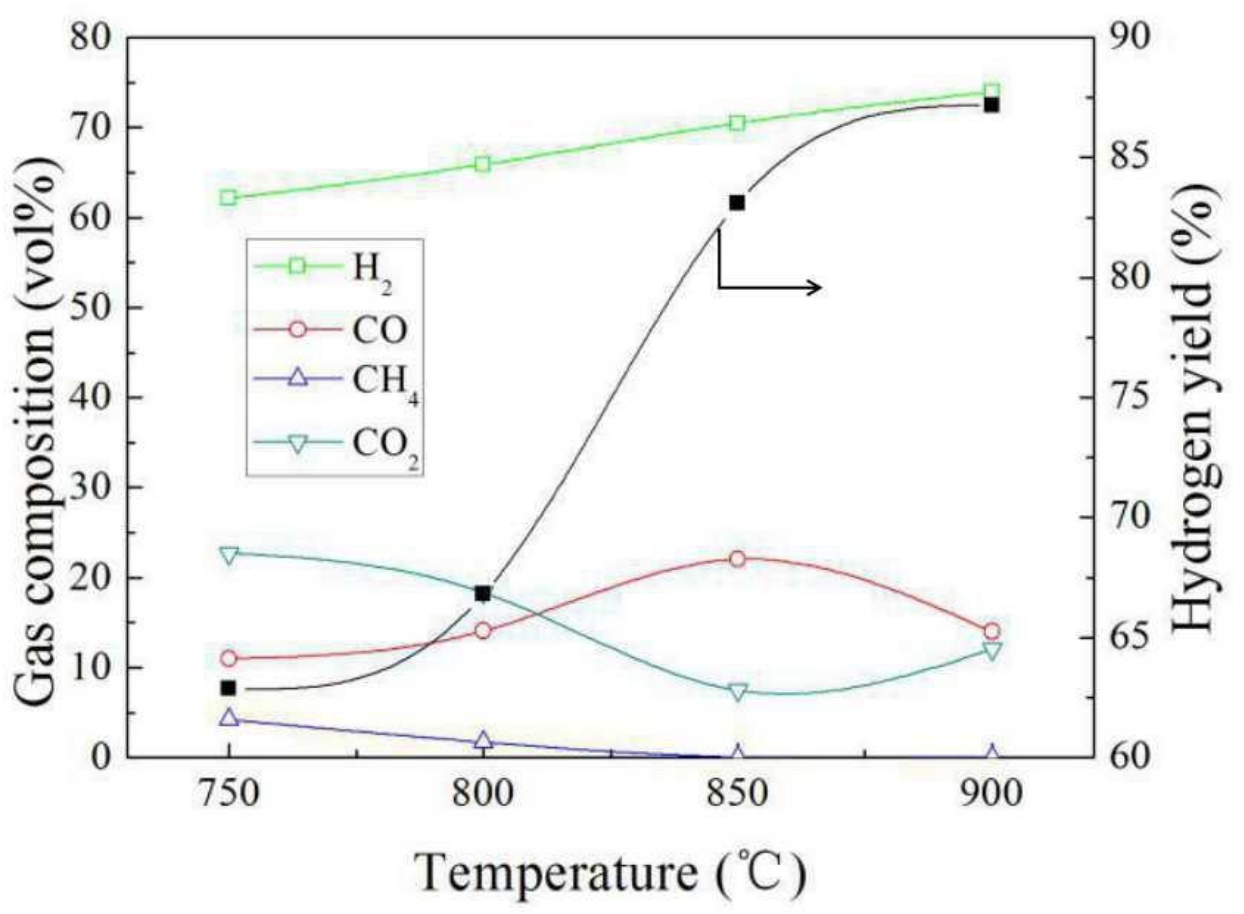

Fig. 2 
Fig. 3

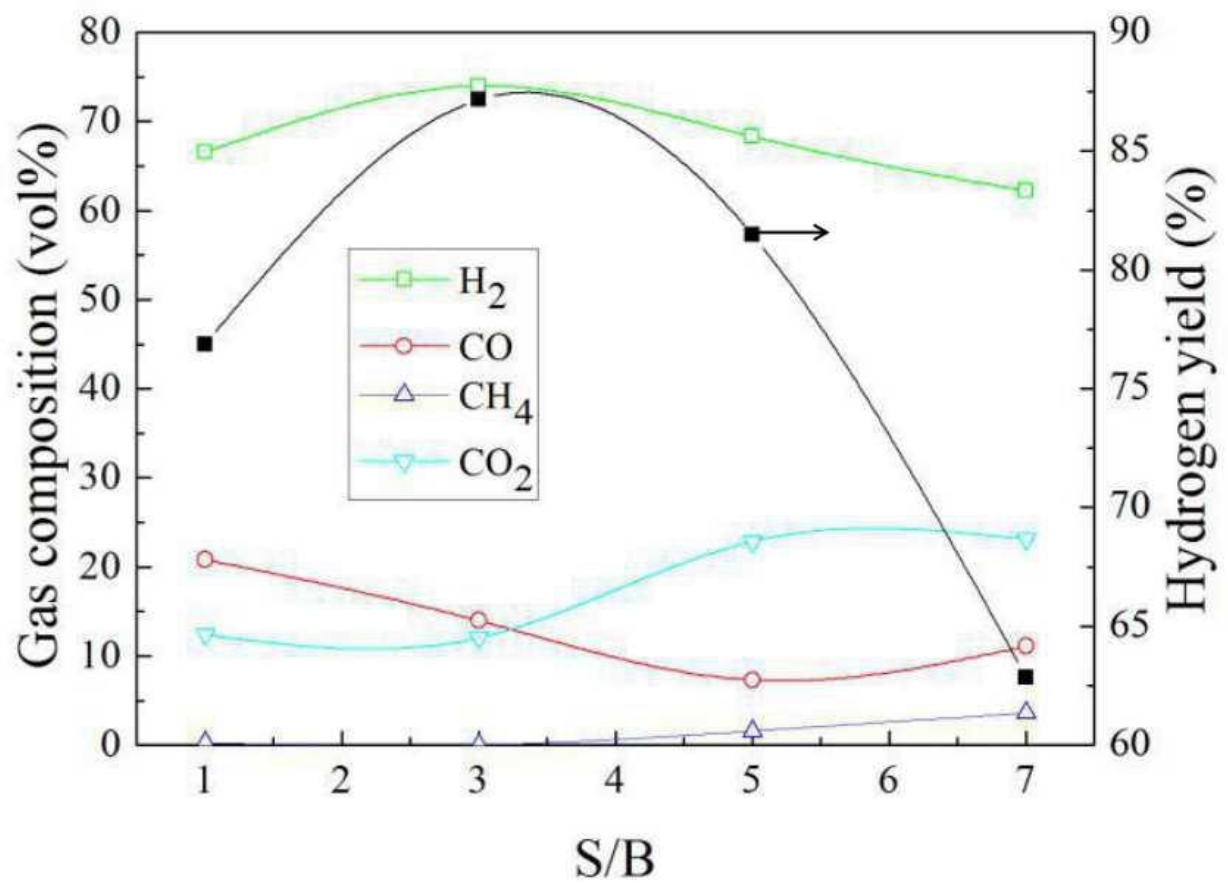


Fig.

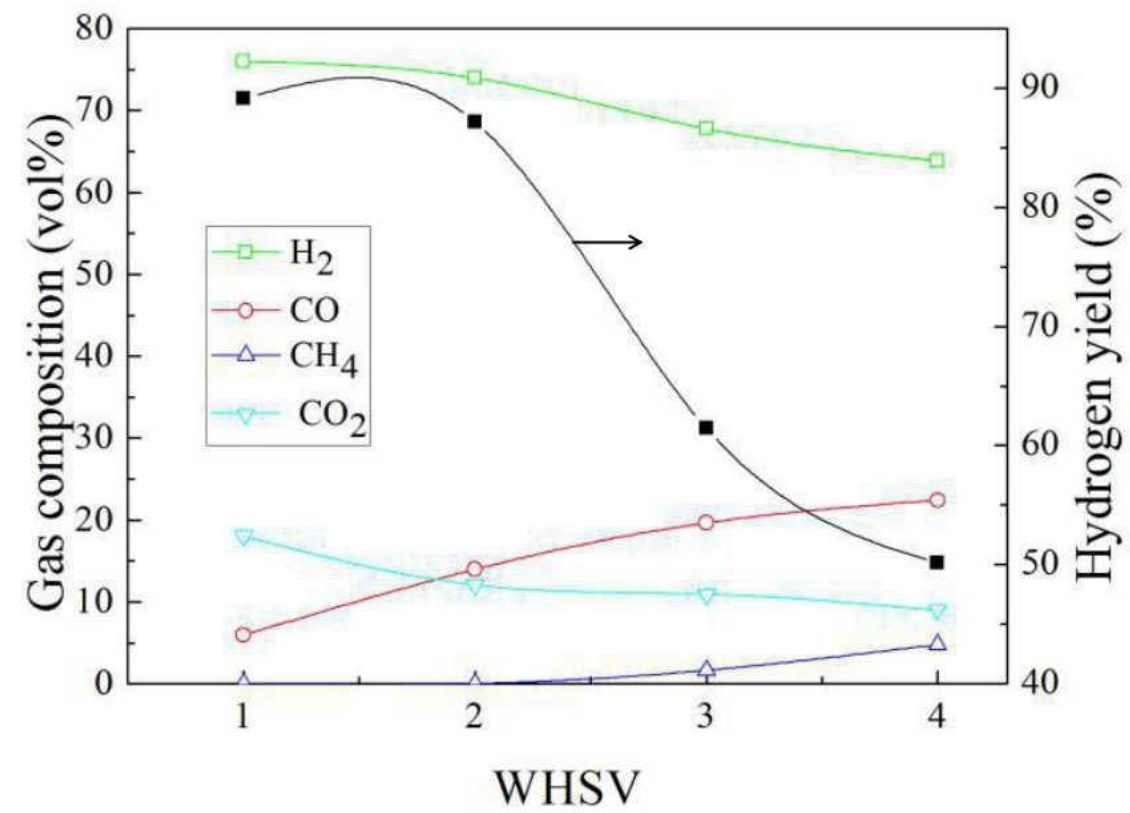


Table 1: Ultimate analysis and proximate analysis of the bio-char. ${ }^{\text {a }}$

\begin{tabular}{|c|c|c|c|c|c|c|}
\hline \multicolumn{4}{|c|}{ Ultimate analysis (wt.\%) } & \multicolumn{3}{c|}{ Proximate analysis (wt.\%) } \\
\hline $\mathrm{C}$ & $\mathrm{H}$ & $\mathrm{O}^{\mathrm{b}}$ & $\mathrm{N}$ & Volatile matter & Fixed carbon & Ash \\
\hline 60.10 & 3.68 & 4.49 & 0.13 & 30.90 & 37.50 & 31.60 \\
\hline
\end{tabular}

${ }^{\mathrm{a}}$ Dry basis. ${ }^{\mathrm{b}}$ By difference.

Table 2: AAEM species analysis of the ash in bio-char (wt.\%).

\begin{tabular}{|c|l|c|c|c|c|c|}
\hline Sample & $\mathrm{Mg}$ & $\mathrm{Ca}$ & $\mathrm{K}$ & $\mathrm{Fe}$ & $\mathrm{Al}$ & $\mathrm{Zn}$ \\
\hline Raw bio-char & 17.16 & 13.18 & 2.10 & 2.16 & 1.71 & 0.22 \\
\hline Acid-treated bio-char & 5.19 & 3.36 & 1.16 & 0.93 & 1.15 & 0.06 \\
\hline
\end{tabular}

Table 3: Ultimate analysis of the bio-char after steam pretreatment. ${ }^{\text {a }}$

\begin{tabular}{|c|c|c|c|c|}
\hline \multicolumn{5}{|c|}{ Ultimate analysis (wt.\%) } \\
\hline $\mathrm{C}$ & $\mathrm{H}$ & $\mathrm{O}^{\mathrm{b}}$ & $\mathrm{N}$ & Ash \\
\hline 6.36 & 0.28 & 0.45 & 0.25 & 92.67 \\
\hline
\end{tabular}

${ }^{a}$ Dry basis. ${ }^{b}$ By difference.

Table 4: The BET test of bio-char after steam pretreatment.

\begin{tabular}{|c|c|c|}
\hline $\begin{array}{c}\text { Surface area } \\
\left(\mathrm{m}^{2} / \mathrm{g}\right)\end{array}$ & $\begin{array}{c}\text { Pore volume } \\
\left(\mathrm{cm}^{3} / \mathrm{g}\right)\end{array}$ & $\begin{array}{c}\text { Average pore size } \\
(\mathrm{nm})\end{array}$ \\
\hline 5.20 & 0.003048 & 4.32 \\
\hline
\end{tabular}

Table 5: Influence of bio-char.

\begin{tabular}{|c|c|c|}
\hline Catalyst & No catalyst & Bio-char \\
\hline Reaction temperature $\left({ }^{\circ} \mathrm{C}\right)$ & 800 & 800 \\
\hline S/B & 3 & 3 \\
\hline WHSV & 2 & 2 \\
\hline Gas composition & & \\
\hline $\mathrm{H}_{2}$ content $($ vol\%) & 50.74 & 65.91 \\
\hline $\mathrm{CO}$ content $($ vol\%) & 17.83 & 14.08 \\
\hline $\mathrm{CH}_{4}$ content $($ vol\%) & 10.24 & 1.68 \\
\hline $\mathrm{CO}_{2}$ content $($ vol\%) & 21.19 & 18.33 \\
\hline $\mathrm{Hydrogen}$ yield $(\%)$ & 38.16 & 66.80 \\
\hline
\end{tabular}


Table 6: Effect of AAEM species on the catalytic activity of bio-char.

\begin{tabular}{|c|c|c|}
\hline Catalyst & Acid-treated bio-char & Raw bio-char \\
\hline Reaction temperature $\left({ }^{\circ} \mathrm{C}\right)$ & 900 & 900 \\
\hline S/B & 3 & 3 \\
\hline WHSV & 1 & 1 \\
\hline Gas composition & & 75.97 \\
\hline $\mathrm{H}_{2}$ content $($ vol\%) & 67.82 & 5.95 \\
\hline $\mathrm{CO}$ content $($ vol\%) & 18.15 & 0 \\
\hline $\mathrm{CH}_{4}$ content $($ vol\%) & 0 & 18.08 \\
\hline $\mathrm{CO}_{2}$ content $($ vol\%) & 14.03 & 89.13 \\
\hline $\mathrm{Hydrogen}$ yield $(\%)$ & 70.22 & \\
\hline
\end{tabular}

